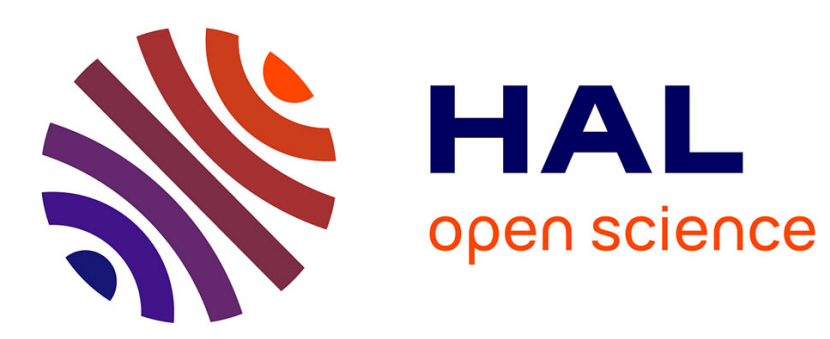

\title{
The Sustainability and Outreach of Microfinance Institutions
}

\author{
Jaehun Sim, Vittaldas V. Prabhu
}

\section{To cite this version:}

Jaehun Sim, Vittaldas V. Prabhu. The Sustainability and Outreach of Microfinance Institutions. IFIP International Conference on Advances in Production Management Systems (APMS), Sep 2014, Ajaccio, France. pp.286-293, 10.1007/978-3-662-44736-9_35 . hal-01387880

\section{HAL Id: hal-01387880 \\ https://hal.inria.fr/hal-01387880}

Submitted on 26 Oct 2016

HAL is a multi-disciplinary open access archive for the deposit and dissemination of scientific research documents, whether they are published or not. The documents may come from teaching and research institutions in France or abroad, or from public or private research centers.
L'archive ouverte pluridisciplinaire HAL, est destinée au dépôt et à la diffusion de documents scientifiques de niveau recherche, publiés ou non, émanant des établissements d'enseignement et de recherche français ou étrangers, des laboratoires publics ou privés. 


\title{
The Sustainability and Outreach of Microfinance Institutions
}

\author{
Jaehun Sim and Vittaldas V. Prabhu \\ The Harold and Inge Marcus Department of \\ Industrial and Manufacturing Engineering \\ 310 Leonhard Building \\ University Park, PA 16802 \\ jus238@psu.edu and prabhu@engr.psu.edu
}

\begin{abstract}
Microfinance emerged as an approach with great potential for alleviating poverty and improving access to financial services by offering small loans with no pledged collateral requirement. Due to the growing demand for microfinance, businesses have put more emphasis on the relationship between financial sustainability and outreach. Microfinance Institutions (MFIs) work to increase social sustainability by providing more services to particular clientele, while maintaining the financial and operational sustainability of the institutions. This study investigates the financial sustainability and outreach of 32 MFIs in India in terms of interest rate and default rate. This study employs a simple methodology for the evaluation of microcredit interest rates proposed by $\mathrm{Mu}$ hammad Yunus (2007), along with a new methodology for the evaluation of microcredit default rates. As a preliminary stage of using the Black-Scholes (BS) model, this study tests the validation of MFIs' asset values and default rates of geometric Brownian motion (GBM) using data. The Ryan-Joiner test is used to check the independence of data, and the chi-square test on two-way tables is used to check the serial independence of data. The interest rate premium and the default rate from the BS model will facilitate making decisions on the sustainability and outreach of MFIs.
\end{abstract}

Keywords: Microfinance, Interest Rate Premium, and Default Rate Premium

\section{Introduction}

After the success of various MFIs over the past decades, microfinance has become a key tool for alleviating poverty and offering financial services to the poor in both developing and underdeveloped countries. MFIs provide the poor with both financial resources such as small loans with no pledged collateral requirement, savings, and insurance, and social services such as health care and education (Sengupta and Aubuchon, 2008).

During the growth of microfinance, MFIs have increased social sustainability by providing additional services to particular clientele in remote and rural areas, while 
keeping the financial and operational sustainability of the institutions (Hartarska, 2002). As a result, MFIs require more investments to meet the growing demand.

For instance, the World Bank estimates that more than $87 \%$ of the vulnerable people still have limited access to financial services in India (The World Bank Group, 2005). Since there is a limit to the amount of investments from donors, it is critical for MFIs to find a way to maintain financial and operational self-sustainability while expanding the breadth and depth of outreach.

MFIs primarily derive income from the interest earnings of their loan portfolios. Thus they have found it necessary to charge high interest to cover their major costs. The average interest rate MFIs charge is $38 \%$, which is high compared to regular commercial financial institutions. A consequence of such a high interest rate is that MFIs experience difficulty in increasing outreach toward target clientele in remote and rural areas.

Along with high interest rates, another principal issue in microfinance is the high default rate. The default rate issue is a major impediment to MFIs increasing their outreach. MFIs experience difficulty in maintaining financial sustainability because they do not have any mechanism of contract enforcement to collect on their loans.

To analyze MFIs' microcredit interest rates, this study employs a simple methodology for the evaluation of the microcredit interest rates proposed by Muhammad Yunus (2007) based on an interest rate premium. The interest rate premium is calculated by subtracting the cost of funds at the market rate paid by the MFI from the interest rate charged by the MFI. The simple evaluation methodology classifies MFIs into three zones -- green zone, yellow zone, and red zone -- based on the interest rate premium to investigate MFIs' operations. For instance, if an MFI has fallen into the red zone, the MFI's main objective is on profit maximization, not on social missions.

The GBM process has been widely used for describing quantity moves over time with uncertainty, such as in the stock market. As a preliminary stage of using the BS model, this paper first tests whether MFIs' asset values as the value of MFIs follow GBM, based on the study of Marathe and Ryan (2005).

The rest of this paper is organized into four sections. Section Two provides a review of the relevant literature on the sustainability and outreach of microfinance. In Section Three, the geometric Brownian motion validation methodology is presented, along with the methodology for an interest rate premium evaluation. Section Four presents numerical examples through the Indian MFIs case with discussion. Finally, the conclusion is provided in Section Five.

\section{Literature Review}

Since the debate between the financial sustainability and outreach of MFIs in the 1990s, MFIs have increasingly had to consider both profit maximization and social mission as part of their operations. Increasing outreach to the poor cannot be achieved without solid financial sustainability of MFIs. Despite the growing emphasis towards sustainability and outreach, there has not been much research conducted in this regard.

Cull et al. (2007) conduct empirical tests for 124 MFIs in 49 countries to gain a better understanding of specific aspects of financial performance and the depth of 
outreach. The study shows that an individual contract-based MFI makes better profits compared with a group contract-based MFI. The study also shows that an individual contract-based MFI increasingly focuses on wealthier clients and dramatically lowers the fraction of both poor and female clients. The study also shows that a high level of fees does not guarantee a high profit.

Hermes et al. (2010) investigate the relationships of the trade-off between sustainability and outreach by analyzing 435 MFIs from 1997 to 2007. The study measures sustainability in terms of cost efficiency and the depth of outreach in terms of the average loan balance, average saving balance, and percentage of women clients. The study indicates that efficient operations in MFIs are helpful for improving financial sustainability.

Cull et al. (2010) investigate how prudential regulation and supervision affect sustainability and outreach of MFIs, using the data of the largest 245 MFIs. The study shows that supervision increases an MFI's average loan balance and decreases the fraction of female clients. Social mission-oriented MFIs significantly reduce their profitability without adjusting loan sizes and fraction of women clients under supervision.

Hudson and Traca (2010) examine how subsidy affects the efficiency of MFIs, based on microfinance rating data of 100 MFIs. The study indicates that the subsidy intensity positively affects the efficiency of MFIs under a certain level. Wydick et al. (2010) employ an elasticity of social imitation to investigate the determinants of outreach of MFIs. The study provides evidence that the magnitude of the social network, such as a church network, plays an important role in the breadth and depth of outreach.

Sim and Prabhu (2013) consider a supply chain microfinance model as a financial sustainability solution in microfinance. Using a game theoretical analysis, the study investigates how investment levels, raw material prices, and manufacture margins are influenced by loan interest rates under three types of decentralized channel policies.

In summary, the literature review shows a relationship between sustainability and outreach of MFIs. It is clear that a marginal increment of financial sustainability in terms of profit creates a marginal reduction of outreach of MFIs. However, it is difficult to determine how a marginal increment of outreach affects a marginal improvement of financial sustainability in microfinance.

\section{$3 \quad$ Methodology}

The objective of this study is to investigate the financial sustainability and outreach of MFIs in terms of interest rate and default rate. In the first stage, this study uses a simple evaluation methodology for microcredit interest rates based on the interest rate premium. In the second stage, as a preliminary to using the BS model, this study tests the validation of MFIs' asset values and default rates of GBM. 


\subsection{Microcredit Interest and Default Rate Evaluation}

This section reviews Dr. Yunus's methodology for the evaluation of microcredit interest rates (Yunus, 2007). Based on an interest rate premium, the methodology analyzes MFIs' operations and classifies the MFIs into three zones, as shown in Table 1. The interest rate premium is equal to the difference between the interest rate and the cost of funds. In microfinance, the interest rate premium is calculated by subtracting the financial expense on loan portfolio dividing by gross loan portfolio from the yield on gross loan portfolio.

$$
\text { Yield on gross loan portfolio- } \frac{\text { Financial Expense on loan portfolio }}{\text { Gross loan portfolio }}
$$

For instance, if a particular MFI's interest rate premium falls into the green zone, it means that the MFI focuses on the poverty reduction mission. On the other hand, if the MFI falls into the red zone, it means that the MFI focuses on the profit maximization mission.

Table 1. The Categorization of an Interest Rate Premium

\begin{tabular}{|c|c|}
\hline Zone & Value \\
\hline Green Zone & $\leq 10 \%$ \\
\hline Yellow Zone & $\leq 15 \%$ \\
\hline Red Zone & $>15 \%$ \\
\hline
\end{tabular}

In a similar way, this study proposes a new methodology, a default rate premium, for the evaluation of microcredit default rates. In microfinance, the default rate premium is the difference between the loan loss rate and the cost of loan default. The default rate premium is calculated by subtracting the impairment loan loss dividing by gross loan portfolio from loan loss rate. If the value of the default rate premium has a negative value, it implies that the MFI needs to increase its loan loss allowance to keep the financial sustainability of the MFI. In a contrast case, the MFI can still focus on the poverty reduction mission.

$$
\text { Loan loss rate- } \frac{\text { Impairment loan loss }}{\text { Gross loan portfolio }}
$$

\subsection{Geometric Brownian Motion Validation}

This section reviews the validation methodology for the GBM proposed by Marathe and Ryan (2005). GBM, defined as the logarithm of randomly varying quantity, follows Brownian motion in a continuous time stochastic process. In order to follow GBM, the data needs to satisfy two assumptions: normality and independence from past data.

This study uses the Ryan-Joiner test, similar to the Shapiro-Wilk test, to check whether the data is normally distributed by detecting all departures from normality. By comparing the correlation between the predicted normal data with actual data, the 
Ryan-Joiner test checks normality on a set of data based on what normally distributed data set of a given sample size would be. If the p-value is greater than the level of significance, the null hypothesis of a normal distribution is not rejected. In this case, the data could plausibly be normally distributed. In this test, the hypothesis set is as follows:

Ho: The distribution is normal

Ha: The distribution is not normal

To test the serial independence of data, the study uses the chi-square test on twoway tables. The test investigates the association between the row and column variables in a two-way table by investigating distributions of categorical variables which differ from one another. If the p-value is greater than the level of significance, the null hypothesis is not rejected. This means that the data could plausibly be serially independent. In this test, the hypothesis set is as follows:

Ho: There is no association between the variables

Ha: There is some association between the variable

\section{$4 \quad$ Numerical Examples}

In this case study, the financial sustainability and outreach of MFIs in five countries: Afghanistan, China, India, Peru, and Tanzania is investigated in terms of interest rate premiums and default rates. The relevant data is obtained through the MIX Market database in 2011 and 2012. In this study, each MFI is considered as one group. At the first stage, the interest rates in five countries are calculated to investigate whether the MFIs focus on their social mission in terms of outreach using Dr. Yunus's methodology.

The interest rate premium is calculated by subtracting the financial expense per gross loan portfolio from the yield on gross loan portfolio. As shown in Figure 1, MFIs fall into the green zone because their interest rate premiums are less than $10 \%$. MFIs belong to the yellow zone because their interest rate premiums are between $10 \%$ and $15 \%$. MFIs fall into the red zone because their interest rate premiums are greater than $15 \%$. Based on this result, it is possible to conclude that some of the analyzed MFIs are attempting to increase their outreach in breadth and depth.

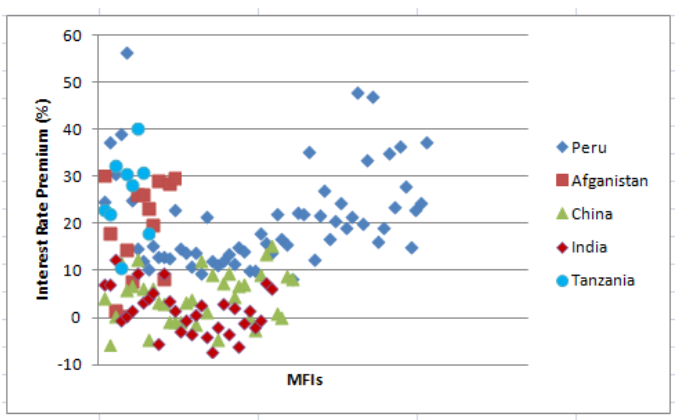

Fig. 1. Interest Rate Premiums 
The default rate premium is calculated by subtracting the loan loss impairment expense per gross loan portfolio from the loan loss rate on gross loan portfolio. As shown in Figure 2, some MFIs fall into the zone around zero, which implies that MFIs need to consider the trade-off between the profit maximization mission and the poverty reduction mission. The positive value of the default rate premium of the MFIs can focus on a poverty reduction mission because of the financial sustainability of the institutions, whereas the negative value of the default rate premium of the MFIs can focus on profit maximization mission because the institution needs to increase its financial sustainability.

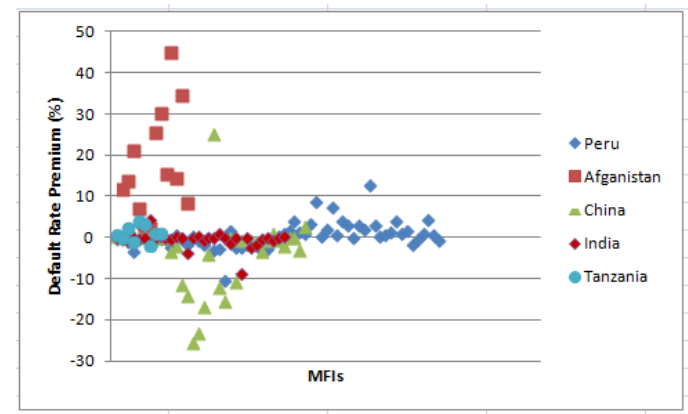

Fig. 2. Default Rate Premiums

Figure 3 illustrates the interest rate premium versus the default rate premium. The MFIs in quadrant one focus on profit maximization mission and the MFIs in quadrant three focus on poverty reduction mission. The MFIs in quadrant three need to attempt to increase profit maximization mission. The MFIs in quadrant two and three need to consider the trade-off between the profit maximization mission and the poverty reduction mission, while considering the institutions' financial sustainability.

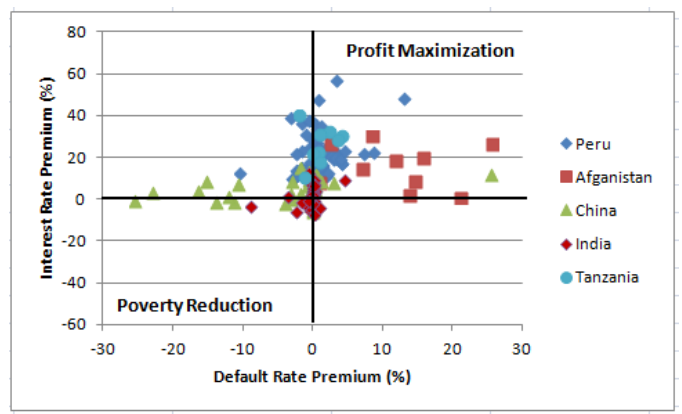

Fig. 3. Interest and Default Rate Premiums Quadrant

In order to use the BS model, the total value of a firm, the value of the underlying assets, needs to follows GBM. Thus, at this stage, the Ryan-Joiner test and the chisquare test on two-way tables are conducted to check the normality and independence of the asset values and the default rates of 32 MFIs in India from 2011 to 2012. In both the Ryan-Joiner test and the chi-square test, the log ratio values of the asset val- 
ues and the default vales are tested. First, the normality test is conducted. As shown in Figure 4, the null hypothesis of a normal distribution is not rejected because the pvalue is greater than 0.1 . Thus, it can be concluded that the asset values could be consistent with the lognormal aspect of GBM.

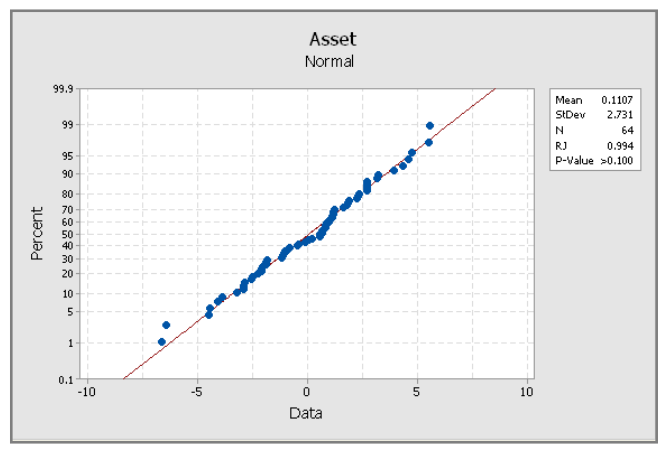

Fig. 4. Normal Probability Plot for Assets

As shown in Figure 5, for the default rate, the null hypothesis of a normal distribution is not rejected because the p-value is greater than 0.1 . Thus, it can be concluded that the default rate values could be consistent with the lognormal aspect of GBM. By knowing the default rate following GBM, it is possible to simulate default rate paths. By predicting the future behavior of the default rate, MFIs can prepare for the impending default risk.

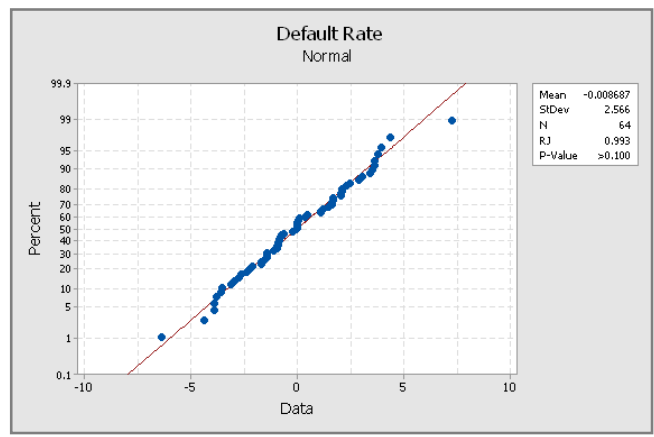

Fig. 5. Normal Probability Plot for Default Rates

Next, the chi-square test on two-way tables is conducted to check the independence of the asset values and the default rates of 32 MFIs in India from 2011 to 2012. The $\log$ ratio values of assets are divided into 4 categories. The null hypothesis of no association cannot be rejected because the p-value, 0.861, is greater than 0.05 . It can be concluded that the asset values are independent. Similarly, the log ration values of default rates are divided into three categories. Since the p-value is 0.495 , which is greater than 0.05 , the null hypothesis of no association cannot be rejected. Thus, it can be concluded that the default rates are independent. 


\section{Conclusion}

This study considers the financial sustainability and outreach of MFIs in terms of the interest rate and the default rate. Dr. Yunus's methodology measures interest rate premiums and the proposed methodology measures default rate premiums for MFIs in five countries to analyze whether the MFIs focus on their social mission in terms of outreach. The results show that some of the analyzed MFIs focus on increasing their outreach in breadth and depth.

As a validation of GBM, the Ryan-Joiner test is used to test the normality of the underlying asset and the default rate, along with the chi-square test for the independence. Since the data follow GBM, the BS model is used to calculate default rates of 32 MFIs in India for 2012. The primary assumption of the widespread risk models in bonds and equities is that the data set follows GBM. By validating both asset and default data following GBM, this study demonstrates that it is possible to employ risk models for the microfinance industry. By measuring key risks, the employed models could be used to reveal risk potential as well as implement risk strategies for MFIs. Ultimately, the MFIs can simultaneously achieve both financial sustainability and social mission.

\section{Reference}

1. Charitou, A., D. Dionysiou, et al. (2013). "Alternative bankruptcy prediction models using option-pricing theory." Journal of Banking \& Finance 37: 2329-2341.

2. Cull, R., A. Demirgüç-Kunt, et al. (2007). "Financial performance and outreach: A global analysis of lending microbanks." The Economic Journal 117(1): 107-133.

3. Cull, R., A. Demirgüç-Kunt, et al. (2010). "The effect of regulation on MFI profitability and outreach." World Development 38.

4. Hartarska, V. (2002). "Three essays on finance for the poor." The Ohio State University.

5. Hermes, N., R. Lensink, et al. (2010). "Outreach and efficiency of microfinance institutions." World Development 38.

6. Hudon, M., and D. Traca (2010). "Subsidies and sustainability in microfinance." World Development 38.

7. Marathe, R. R. and S. M. Ryan (2005). "On the validity of the geometric Brownian motion assumption.” Engineering Economist 50: 159-192.

8. Sengupta, R. and C. P. Aubuchon (2008). "The microfinance revolution: An overview." Federal Reserve Bank of St. Louis Review 90(1): 9-30.

9. Sim, J. and V. Prabhu (2013). "Game theoretical approach to supply chain microfinance." APMS 2013, Part I, IFIP AICT 414: 48-53.

10. The World Bank Group (2005). "Microfinance can be the biggest instrument in the fight against poverty." Year of Micro-credit Conference.

11. The World Bank Group (2005). "Microfinance can be the biggest instrument in the fight against poverty." Year of Micro-credit Conference.

12. Wydick, B., H. Karp, et al. (2010). "Social networks, neighborhood effects and credit access." World Development 38.

13. Yunus, M. (2007). "Creating a world without poverty: Social business and the future of capitalism.” PublicAffairs. 